\title{
Long non-coding RNA ENST00000500843 is downregulated and promotes chemoresistance to paclitaxel in lung adenocarcinoma
}

\author{
XIN TIAN, SONG GAO, YANG LIU, YING XUAN, RONG WU and ZHENYONG ZHANG \\ Department of Medical Oncology, Shengjing Hospital of China Medical University, Shenyang, Liaoning 110004, P.R. China
}

Received December 5, 2018; Accepted June 28, 2019

DOI: $10.3892 / \mathrm{ol} .2019 .10704$

\begin{abstract}
Adenocarcinoma is one of the most common pathological types of human lung cancer and has the highest incidence and mortality rates worldwide. Resistance to paclitaxel (PTX), the standard chemotherapy agent for treatment of lung adenocarcinoma, is a major clinical obstacle. Sensitive markers are urgently required for the diagnosis and characterization of lung cancer, as well as to manage drug resistance. Previous studies have described the activity of long non-coding RNAs (lncRNAs) in human lung cancer and chemotherapy resistance. In previous studies, lncRNA ENST00000500843 was identified to be downregulated in PTX-resistant A549 human lung cancer cells. However, the roles of this lncRNA in the development of lung adenocarcinoma and its mechanism in PTX resistance, to the best of our knowledge, have not been described. In the present study, 56 pairs of lung adenocarcinoma and normal adjacent tissue samples were collected. Reverse transcription-quantitative PCR revealed that the expression levels of 1ncRNA ENST00000500843 were lower in lung adenocarcinoma tissues and PTX-resistant A549 cells when compared with normal adjacent tissues and A549 cells. Decreased expression levels of IncRNA ENST00000500843 in lung adenocarcinoma tissues were associated with tumor diameter, the degree of pathological differentiation and metastasis of lymph nodes. Additionally, patients with low expression levels of ENST00000500843 exhibited poorer overall survival and progression-free survival rates. Furthermore, the present study demonstrated that knockdown of lncRNA ENST00000500843 with small interfering RNA decreased the likelihood of apoptosis in A549 cells and promoted resistance to PTX. This indicated that lncRNA ENST00000500843 may be a useful diagnostic marker of lung cancer and a good prognostic marker for resistance to treatment with PTX.
\end{abstract}

Correspondence to: Dr Zhenyong Zhang, Department of Medical Oncology, Shengjing Hospital of China Medical University, 36 San Hao Street, Shenyang, Liaoning 110004, P.R. China

E-mail: 1369653951@qq.com

Key words: long non-coding RNAs, lung adenocarcinoma, chemoresistance

\section{Introduction}

Lung cancer is one of the leading causes of cancer-associated mortality worldwide, and its incidence, along with aging populations and environmental pollution, is increasing (1). This is leading to a large social and economic burden, which seriously affects the development of health systems and the economy around the world (2). Adenocarcinoma is a major pathological cancer type, and molecular-based targeted therapy is required. Existing therapies include surgery, radiotherapy and chemotherapy with paclitaxel (PTX), all of which exhibit poor survival rates $(3,4)$. Consequently, resistance to PTX is an obstacle for clinical treatment since it affects the curative effect and eventually leads to treatment failure (5). Drug resistance is divided into primary and secondary resistance (6). Previously, investigations into the mechanisms of drug resistance focused on proteins associated with the cell membrane, increased drug metabolism, alterations in cell cycle, cell apoptosis and autophagy disorders, and DNA damage repair ability $(7,8)$. The mechanism behind PTX resistance is multifactorial and complex, and presents a significant challenge in the successful treatment of lung cancer (9). An improved understanding of the molecular mechanism underlying the development of this form of resistance is therefore required. The identification of molecular markers associated with PTX-associated tumor response could help to select patients who are likely to benefit from chemotherapy (10).

In previous years, evidence has increasingly indicated that long non-coding RNAs (IncRNAs) participate in drug resistance via multiple signaling pathways. Abnormal lncRNA expression serves an important role in the regulation of tumor cell apoptosis and drug resistance (11-14). For example, the long intergenic non-coding (LINC) RNA HOX transcript antisense RNA (HOTAIR) is expressed at significantly higher levels in A549 lung adenocarcinoma cells resistant to cisplatin (DDP) compared with A549 cells that are sensitive to DDP, in vitro knockdown of HOTAIR has been demonstrated to reduce DDP resistance in A549 human lung cancer cells (15). It has also been demonstrated that HOTAIR alters the cell cycle by downregulating the cyclin dependent kinase inhibitor 1A signaling pathway; and, therefore, reduces cell apoptosis and enhances drug resistance (15). As another example, lncRNA growth arrest specific 5 (GAS5) has been identified to be downregulated in lung cancer tissues compared with in adjacent normal tissues (16). In addition, the expression levels of lncRNA GAS5 
are significantly downregulated in epidermal growth factor receptor (EGFR)-tyrosine kinase inhibitor (TKI)-resistant lung cancer cells compared with in EGFR-TKI sensitive cells, and in vivo and in vitro experiments demonstrated that GAS5 affects EGFR-TKI resistance by regulating the insulin like growth factor 1 receptor protein (16). As a final example, lncRNA maternally expressed 3 (MEG3), which is located on human chromosome 14q32, has previously been reported as a tumor suppressor (17). It is mainly expressed in normal human tissues, particularly in the brain and pituitary gland. MEG3 has been identified to be abnormally expressed in various types of human cancer, with increased expression regulating the proliferation and apoptosis of non-small cell lung cancer (NSCLC) by activating the p53 protein (18). Additionally, using lncRNA microarray and quantitative PCR (qPCR) assays, Liu et al (19) demonstrated that the expression levels of MEG3 are notably decreased in DDP-resistant A549/DDP cells compared with in sensitive cells. Further experiments demonstrated that MEG3 induces the mitochondrial apoptosis signaling pathway via p53 and $\mathrm{Bcl}-\mathrm{xL}$ activation, leading to alterations in the sensitivity of A549 cells to DDP.

In a previous study, it was identified that IncRNA ENST00000500843 expression is downregulated in PTX-resistant A549 human lung cancer cells (20). The present study investigated the role of lncRNA ENST00000500843 in the development of lung adenocarcinoma and its clinical relevance, as well as its effect on PTX resistance. The results of the present study may provide novel molecular therapeutic targets, and may provide a novel direction to evaluate benefits from chemotherapy and reverse drug resistance in patients with lung adenocarcinoma.

\section{Materials and methods}

Clinical specimens. A total of 56 lung adenocarcinoma and normal adjacent tissue samples ( $>5 \mathrm{~cm}$ from the tumor) were collected at Shengjing Hospital of China Medical University between May 2014 and August 2016. Clinicopathological characteristics of the patients are presented in Table I. These patients included 23 men and 33 women with a median age of 58 years (range, $32-76$ years). None of the patients had received any preoperative chemotherapy or radiotherapy, and none of the patients had a previous history of malignant disease. All tumorous tissue samples were diagnosed histopathologically by professional pathologists from Shengjing Hospital of China Medical University who were blinded to the present study. All specimens were obtained within 15 min after excision from the body and stored in liquid nitrogen prior to reverse transcription (RT)-qPCR. All patients were diagnosed by biopsy and no previous system treatment had been performed on the patients. All patients provided written informed consent and the present study was approved by the Ethics Committee of Shengjing Hospital of China Medical University.

Cell lines and culture. The A549 human lung adenocarcinoma cell line was purchased from the Type Culture Collection of the Chinese Academy of Sciences. A549/PTX cells were established in our laboratory in a previous study (20). Cells were cultured in RPMI-1640 medium supplemented with $10 \%$ FBS and 1\% penicillin-streptomycin (all from Gibco;
Thermo Fisher Scientific, Inc.) at $37^{\circ} \mathrm{C}$ in a humidified incubator with $5 \% \mathrm{CO}_{2}$. The A549/PTX cell culture medium also contained $200 \mathrm{ng} / \mathrm{ml}$ PTX (Bristol-Myers Squibb) to maintain the drug-resistant phenotype. Cells in the logarithmic phase of growth were used in all experimental procedures.

$R T$ - $q P C R$. Total RNA from frozen tissue specimens and cells was extracted using TRIzol ${ }^{\circledR}$ reagent (Takara Bio, Inc.) according to the manufacturer's protocol. The concentration and purity of total RNA were measured on a Nanodrop spectrophotometer (Thermo Fisher Scientific, Inc.). RNA integrity was assessed by electrophoresis on a denaturing agarose gel (1\%) followed by detection with ethidium bromide. Subsequently, total RNA was reverse transcribed using a PrimeScript RT reagent kit with genomic DNA Eraser (Perfect Real Time; Takara Bio, Inc.) according to the manufacturer's protocol. The reaction conditions of reverse transcription were: $42^{\circ} \mathrm{C}$ for $60 \mathrm{~min}, 99^{\circ} \mathrm{C}$ for $5 \mathrm{~min}$ and holding at $4^{\circ} \mathrm{C}$. RT-qPCR analyses were conducted using the SYBR Green assay (Takara Bio, Inc.). Thermocycling conditions were as follows: One cycle of $95^{\circ} \mathrm{C}$ for $10 \mathrm{~min}, 95^{\circ} \mathrm{C}$ for $15 \mathrm{sec}$, followed by 40 cycles of $60^{\circ} \mathrm{C}$ for $1 \mathrm{~min}$. IncRNA ENST00000500843 primers were designed using Primer (version 5.0; Premier, Inc.). All experiments were repeated three times. The primer sequences were: ENST00000500843 forward, 5'-CCTGGC TGAGGTGAATAA-3' and reverse, 5'-TTGGACCCGAAC ATCTG-3'; GAPDH forward, 5'-TGCACCACCAACTGCTTA GC-3' and reverse, 5'-GGCATGGACTGTGGTCATGAG-3'. The relative gene expression levels of ENST00000500843 were determined using the $2^{-\Delta \Delta \mathrm{Cq}}$ method (21).

Cell transfection. Three small interfering RNAs (siRNAs) targeting lncRNA ENST00000500843 (siRNA-135, siRNA-197 and siRNA-7) were synthesized by the Jima Corporation (Shanghai GenePharma Co., Ltd.). The sequences of the siRNAs were as follows: siRNA-135 forward, 5'-CAA UUCUCAUCAUGUCAUAUC-3' and reverse, 5'-UAUGAC AUGAUGAGAAUUGCA-3'; siRNA-197 forward, 5'-CUU AUUGCUGAAUAUUGAACU-3' and reverse, 5'-UUCAAU AUUCAGCAAUAAGUC-3'; siRNA-7 forward, 5'-GCUGAA UAUUGAACUUGAUCA-3' and reverse, 5'-AUCAAGUUC AAUAUUCAGCAA-3'; negative control forward, 5'-UUC UCCGAACGUGUCACGUTT-3' and reverse, 5'-ACGUGA CACGUUCGGAGAATT-3'. All three siRNAs (10 nM) were transfected into A549 cells $\left(1 \times 10^{5}\right.$ cells/well) using Lipofectamine ${ }^{\circledR} 2000$ (Invitrogen; Thermo Fisher Scientific, Inc.) according to the manufacturer's protocol. The efficiency of knockdown was detected $36 \mathrm{~h}$ later using RT-qPCR analysis with the aforementioned methodology, and the most stable cells were selected for downstream processes. Subsequent experimentation was performed $36 \mathrm{~h}$ after transfection.

Chemoresistance assay. To evaluate differences in chemoresistance, A549 cells ( $5 \times 10^{3} /$ well) transfected with siRNA or negative control RNA were seeded in 96-well plates and incubated at $37^{\circ} \mathrm{C}$ for $36 \mathrm{~h}$. Following initial incubation, $10 \mathrm{ng} / \mathrm{ml}$ PTX was added to the cells, which were further incubated at $37^{\circ} \mathrm{C}$ in a humidified atmosphere containing $5 \% \mathrm{CO}_{2}$ for 24 h. Subsequently, $10 \mu \mathrm{l}$ Cell Counting Kit-8 reagent (CCK-8; Dojindo Molecular Technologies, Inc.) was added to each 
Table I. Association between lncRNA ENST00000500843 expression and clinicopathological features of patients with lung adenocarcinoma.

\begin{tabular}{|c|c|c|c|}
\hline \multirow[b]{2}{*}{$\begin{array}{l}\text { Clinical } \\
\text { characteristic }\end{array}$} & \multicolumn{2}{|c|}{$\begin{array}{c}\operatorname{lncRNA} \\
\text { ENST00000500843 }\end{array}$} & \multirow[b]{2}{*}{ P-value } \\
\hline & $\begin{array}{c}\text { Low } \\
\text { expression } \\
(\mathrm{n}=45)\end{array}$ & $\begin{array}{c}\text { High } \\
\text { expression } \\
(\mathrm{n}=11)\end{array}$ & \\
\hline \multicolumn{4}{|l|}{ Sex } \\
\hline Male & 19 & 4 & \multirow[t]{2}{*}{0.990} \\
\hline Female & 26 & 7 & \\
\hline \multicolumn{4}{|l|}{ Age, years } \\
\hline$<60$ & 25 & 6 & \multirow[t]{2}{*}{$>0.999$} \\
\hline$\geq 60$ & 20 & 5 & \\
\hline \multicolumn{4}{|l|}{ Smoking status } \\
\hline Yes & 24 & 7 & \multirow[t]{2}{*}{0.781} \\
\hline No & 21 & 4 & \\
\hline \multicolumn{4}{|l|}{ Tumor diameter, $\mathrm{cm}$} \\
\hline$<2$ & 13 & 8 & \multirow[t]{2}{*}{0.019} \\
\hline$\geq 2$ & 32 & 3 & \\
\hline \multicolumn{4}{|c|}{ Pathological differentiation } \\
\hline Moderate and low & 36 & 4 & \multirow[t]{2}{*}{0.012} \\
\hline High & 9 & 7 & \\
\hline \multicolumn{4}{|l|}{$\begin{array}{l}\text { Metastasis of lymph } \\
\text { nodes }\end{array}$} \\
\hline No & 15 & 8 & \multirow[t]{2}{*}{0.041} \\
\hline Yes & 30 & 3 & \\
\hline \multicolumn{4}{|l|}{ TNM stage } \\
\hline I, II & 35 & 7 & \multirow[t]{2}{*}{0.560} \\
\hline III, IV & 10 & 4 & \\
\hline
\end{tabular}

Independent Student's t-test and one-way ANOVA was used to compare the differences between two groups using SPSS software (version 18.0; SPSS, Inc.). Pathological differentiation was concluded by pathological pathologists from Shengjing Hospital of China Medical University using hematoxylin-eosin staining. TNM, Tumor-Node-Metastasis (22); lncRNA ENST00000500843, long noncoding RNA ENST00000500843.

well $(10 \%)$, and cells were incubated at $37^{\circ} \mathrm{C}$ for another $4 \mathrm{~h}$. The absorbance of each well was determined using an ELISA reader (NanoDrop ND-1000; Thermo Fisher Scientific, Inc.) at a wavelength of $450 \mathrm{~nm}$. Three independent experiments were performed with five duplicate wells.

Cell apoptosis analysis. Cell apoptosis was detected by flow cytometry. The cells $\left(5 \times 10^{3}\right.$ cells/well) were cultured at $37^{\circ} \mathrm{C}$ with $10 \mathrm{ng} / \mathrm{ml}$ PTX for $24 \mathrm{~h}$ after transfection. Cells were then double stained using an Annexin V-FITC apoptosis detection kit (BD Pharmingen; BD Biosciences) according to the manufacturer's protocol. Cells were analyzed using a flow cytometer and CellQuest software (version 3.0; BD Biosciences). Cells were classified as viable, dead, early apoptotic or late apoptotic.
The percentages of early apoptotic and late apoptotic cells were calculated and compared.

Statistical analysis. Data were analyzed using SPSS version 18.0 (SPSS, Inc.) and GraphPad Prism version 5.0 (GraphPad Software, Inc.) software. The expression levels of IncRNA ENST00000500843 in lung adenocarcinoma tissues were categorized as low or high expression according to the mean value. Survival curves were estimated using the Kaplan-Meier method, and P-values were obtained using log-rank test. An independent samples t-test was used to compare the differences between two groups and one-way ANOVA with the Bonferroni test used as the post-hoc test using SPSS software (version 18.0; SPSS, Inc.). All experiments were performed at least three times, therefore the data were calculated as the mean \pm standard deviation, and $\mathrm{P}<0.05$ was considered to indicate a statistically significant difference.

\section{Results}

lncRNA ENST00000500843 is downregulated in lung adenocarcinoma tissues and A549/PTX cells. The present study compared the expression levels of IncRNA ENST00000500843 in lung adenocarcinoma and normal adjacent tissue samples. Total RNA was isolated from the tissue samples, and RT-qPCR analysis was performed to examine the expression levels of lncRNA ENST00000500843. The data demonstrated that the expression levels of lncRNA ENST00000500843 were markedly decreased in lung adenocarcinoma tissues compared with in normal adjacent tissues $(\mathrm{P}<0.05$; Fig. 1A). Additionally, the present study examined lncRNA ENST00000500843 expression in A549/PTX and normal lung adenocarcinoma A549 cell lines. As presented in Fig. 1B, RT-qPCR analysis indicated that the expression levels of lncRNA ENST00000500843 were significantly decreased in A549/PTX cells compared with in A549 cells.

lncRNA ENST00000500843 expression is associated with clinicopathological characteristics. To further investigate the clinical significance of lncRNA ENST00000500843 in lung adenocarcinoma, the association between its expression and the clinicopathological characteristics of patients with lung adenocarcinoma was evaluated. In relation to the mean value (5.24), the 56 patients were divided into lncRNA ENST00000500843 high $(n=11)$ and low $(n=45)$ expression groups. The present study revealed that the expression levels of lncRNA ENST00000500843 in lung adenocarcinoma tissue were associated with tumor diameter, the degree of pathological differentiation and metastasis of lymph nodes (Table I; $\mathrm{P}<0.05)$. However, no association was identified between lncRNA ENST00000500843 expression and patient sex, age, smoking status and TNM stage ( $P>0.05$; Table I) (22). These findings suggested that the decreased expression level of lncRNA ENST00000500843 is involved in the malignant progression of lung adenocarcinoma.

Downregulation of IncRNA ENST00000500843 is associated with poor prognosis. The present study further analyzed the association between IncRNA ENST00000500843 expression and the survival time of patients with lung adenocarcinoma. 
A

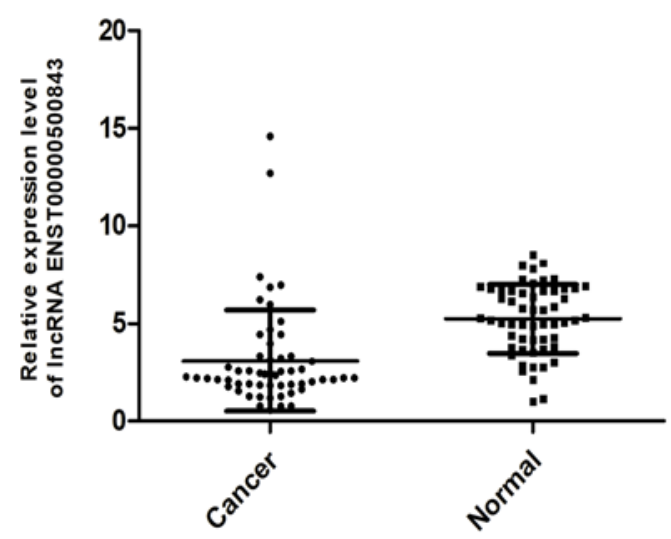

B

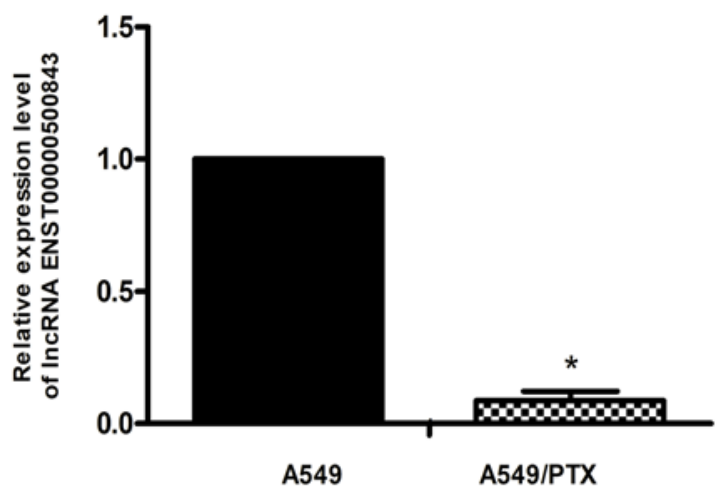

Figure 1. Expression levels of lncRNA ENST00000500843 in lung adenocarcinoma tissue and A549/PTX cells. (A) Expression levels of lncRNA ENST00000500843 were lower in lung adenocarcinoma tissues compared with in normal lung tissues. (B) Expression levels of lncRNA ENST00000500843 were lower in A549/PTX cells compared with in A549 cells. "P<0.05 vs. adjacent tissue or A549. A549/PTX, paclitaxel-resistant A549 cells; lncRNA, long non-coding RNA.
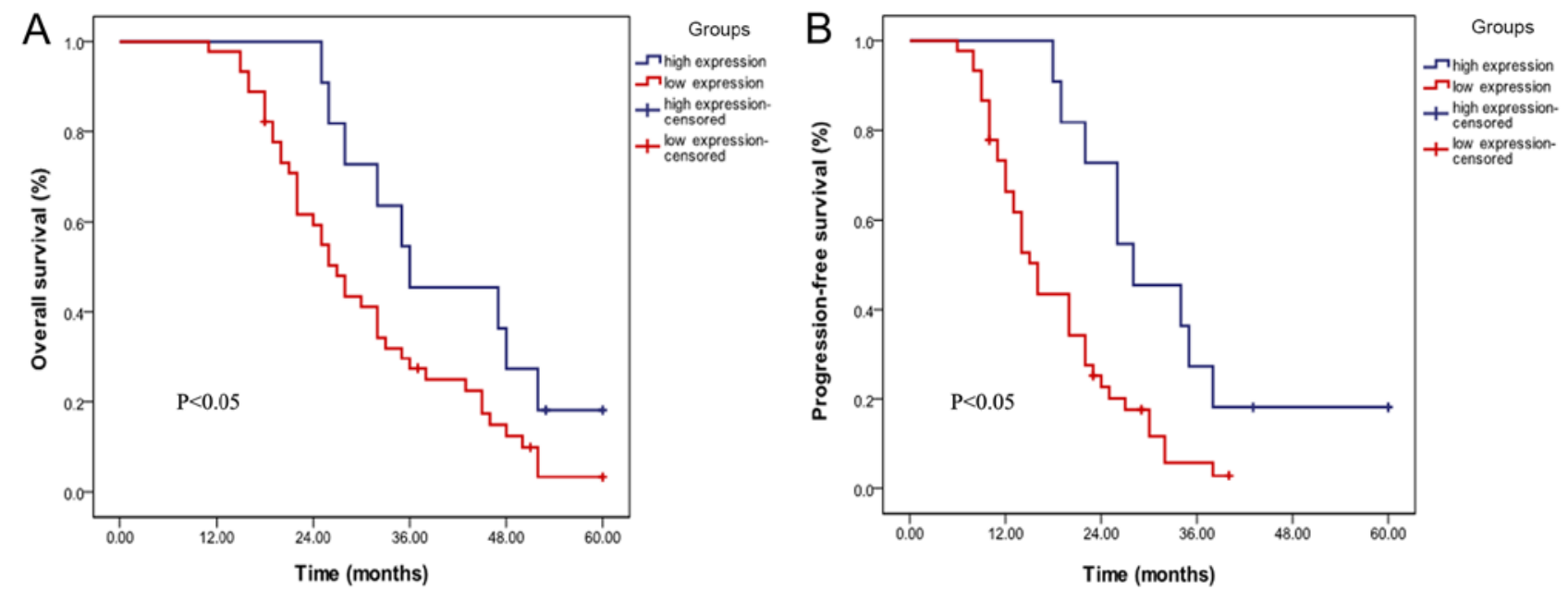

Figure 2. Association between lncRNA ENST00000500843 and progression of lung adenocarcinoma. (A) Patients with low expression levels of lncRNA ENST00000500843 exhibited poorer overall survival rates. (B) Patients with low expression levels of lncRNA ENST00000500843 exhibited poorer progression-free survival rates. lncRNA, long non-coding RNA.

Kaplan-Meier survival analysis was performed to estimate the association between IncRNA ENST00000500843 expression and the prognosis of patients with lung adenocarcinoma. It was demonstrated that patients with low expression levels of ENST00000500843 exhibited significantly poorer overall survival (OS; $\mathrm{P}<0.05$; Fig. $2 \mathrm{~A}$ ) and progression-free survival (PFS; $\mathrm{P}<0.05$; Fig. $2 \mathrm{~B}$ ) rates. The data suggested that patients with lung adenocarcinoma with lower lncRNA ENST00000500843 expression exhibited a worse prognosis compared with those with high expression levels of lncRNA ENST00000500843.

siRNA significantly decreases the expression levels of lncRNA ENST00000500843. In order to further study the association between ENST00000500843 and PTX resistance, siRNA-135, siRNA-197 and siRNA-7 were synthesized. As shown in Fig. 3A, compared with the negative control, all three siRNAs inhibited ENST00000500843 expression to varying degrees, with the strongest inhibition being observed for siRNA-7. The results suggested that ENST00000500843 expression was significantly downregulated following successful siRNA-7 transfection. Therefore, siRNA-7 was used for subsequent experiments.

Knockdown of IncRNA ENST00000500843 promotes chemoresistance to PTX in A549 cells. In order to investigate whether downregulation of ENST00000500843 impaired the resistance of A549 cells to PTX, A549 cells transfected with either siRNA-7 or control RNA were exposed to $10 \mathrm{ng} / \mathrm{ml}$ PTX for $24 \mathrm{~h}$. Cell viability was calculated using the CCK-8 cytotoxicity assay. Compared with ENST00000500843 control cells, A549-siRNA knockdown cells exhibited significantly higher viability in a $10 \mathrm{ng} / \mathrm{ml}$ PTX atmosphere and, thus, less sensitivity to PTX (Fig. 3B). The results indicated that 

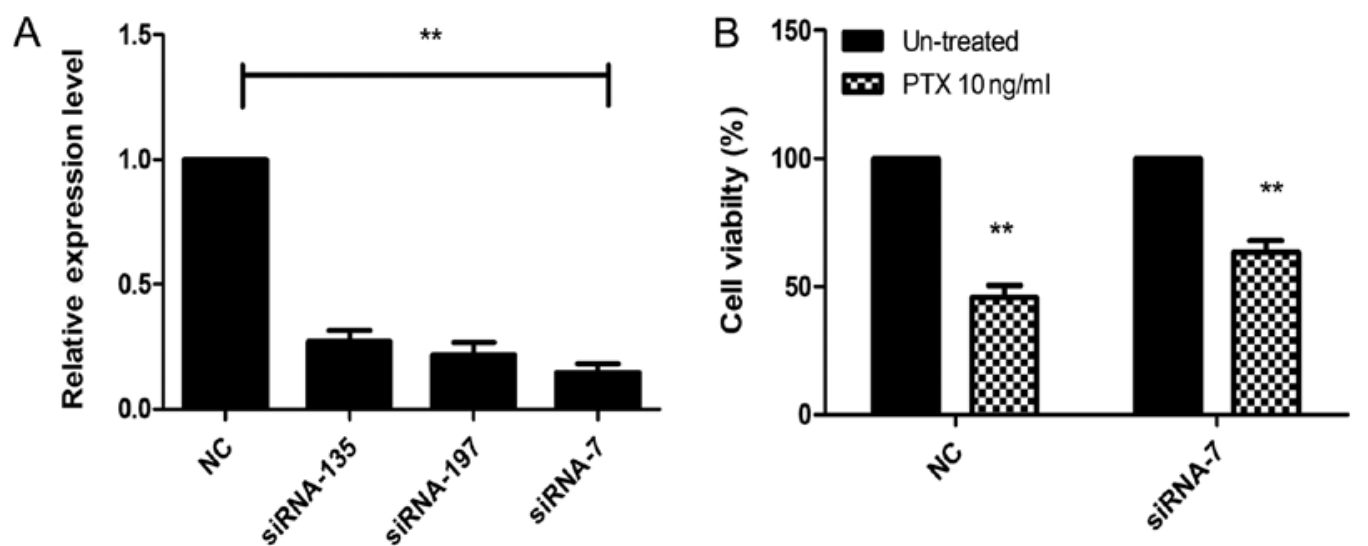

Figure 3. Knockdown of lncRNA ENST00000500843 increased chemoresistance to PTX in A549 cells. (A) After $36 \mathrm{~h}$ of transfection, relative expression levels of ENST00000500843 in A549 cells were measured by reverse transcription-quantitative PCR. Transfection of siRNA-135, siRNA-197 and siRNA-7 targeting ENST00000500843 significantly downregulated lncRNA ENST00000500843 expression in A549 cells, and siRNA-7 exhibited the most marked transfection efficiency. (B) Following transfection of siRNA-7, A549 cells were exposed to $10 \mathrm{ng} / \mathrm{ml}$ PTX for $24 \mathrm{~h}$ and cell viability was assessed by a Cell Counting kit-8 assay. Downregulation of ENST00000500843 increased resistance to PTX. ${ }^{* *} \mathrm{P}<0.01$ vs. si-NC; lncRNA, long non-coding RNA; NC, negative control; PTX, paclitaxel; siRNA, small interfering RNA.

A
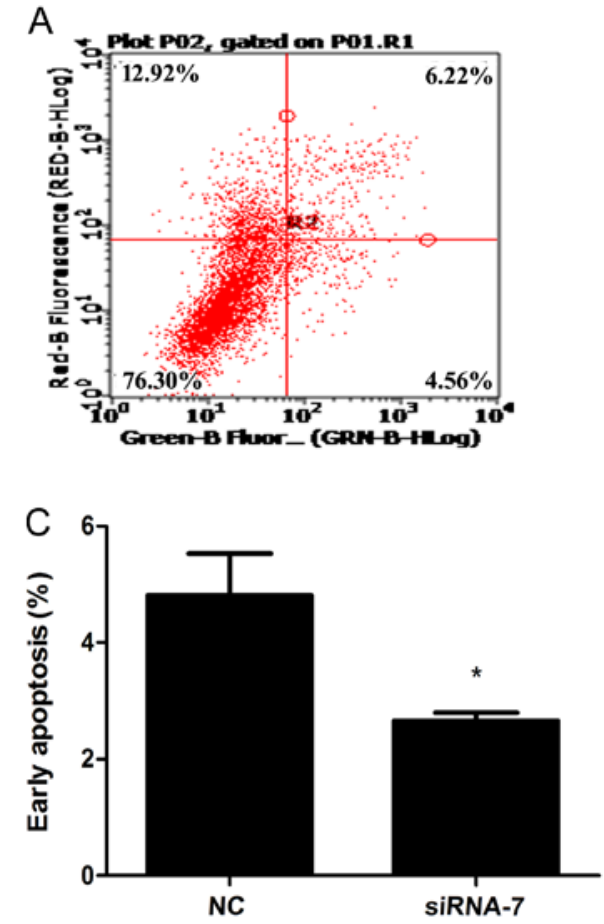

$\mathrm{B}$
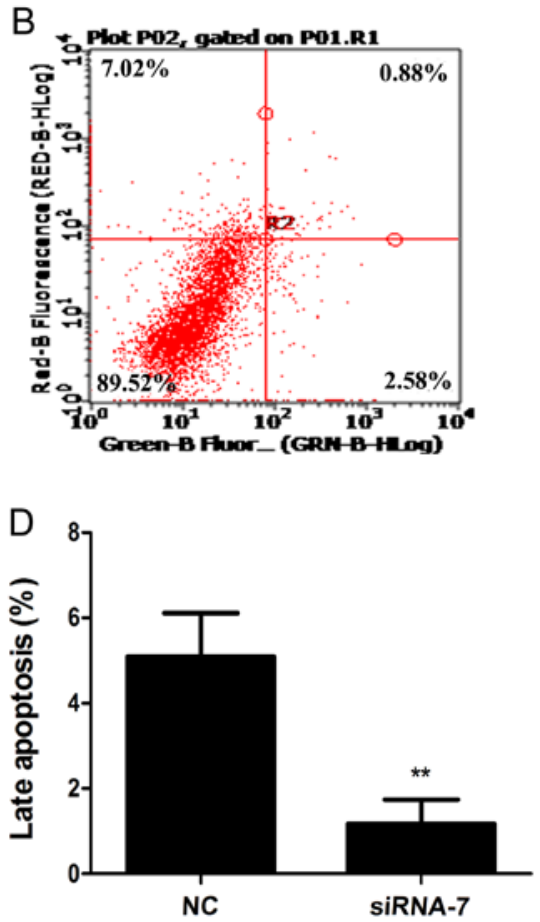

Figure 4. Knockdown of lncRNA ENST00000500843 decreases apoptosis in A549 cells and promotes resistance of lung adenocarcinoma cells to PTX. (A) Flow cytometric analysis of apoptosis in the NC group. (B) Flow cytometric analysis of apoptosis in transfection group. (C) Early apoptosis rates of NC and transfection groups when treated with $10 \mathrm{ng} / \mathrm{ml}$ PTX. (D) Late apoptosis rates of NC and transfection groups when treated with $10 \mathrm{ng} / \mathrm{ml}$ PTX. "P<0.05 and ${ }^{* * *} \mathrm{P}<0.01$ vs. NC lncRNA, long non-coding RNA; NC, negative control; PTX, paclitaxel; siRNA, small interfering RNA.

downregulated expression of lncRNA ENST00000500843 may promote PTX resistance in A549 cells.

Knockdown of IncRNA ENST00000500843 results in decreased levels of apoptosis in A549 cells and promotes lung adenocarcinoma resistance to PTX. To identify the mechanisms by which downregulated ENST00000500843 expression could contribute to PTX resistance, the present study assessed the effect that siRNA-induced knockdown of ENST00000500843 had on cell apoptosis. Following incubation with $10 \mathrm{ng} / \mathrm{ml}$ PTX, the results revealed that siRNA-7 bound to ENST00000500843 decreased the percentage of cells undergoing early and late apoptosis compared with the control siRNA (Fig. 4). Therefore, IncRNA ENST00000500843 could functionally modulate PTX-associated apoptosis and cell survival in A549 cells.

\section{Discussion}

The present study demonstrated that the expression levels of lncRNA ENST00000500843 were significantly downregulated in lung adenocarcinoma tissues and A549/PTX cells 
compared with normal adjacent tissues and A549 cells. Additionally, it was demonstrated that the expression levels of IncRNA ENST00000500843 in lung adenocarcinoma were associated with tumor diameter, the degree of pathological differentiation, metastasis of lymph nodes and prognosis. Further experiments revealed that downregulation of lncRNA ENST00000500843 decreased the rate of apoptosis in A549 cells exposed to PTX, which led to the resistance of lung adenocarcinoma cells to PTX. The present study investigated the role of IncRNA ENST00000500843 in the development of lung adenocarcinoma and its clinical relevance, as well as its effect on PTX resistance.

IncRNA ENST00000500843 is located on human chromosome $8,737 \mathrm{bp}$ long and is categorized as belonging to the long intergenic non-coding RNA family (ENSEMBL; http://asia.ensembl.org/Homo_ sapiens/Transcript/Summary?db=core;g=ENSG00000247134; $\mathrm{r}=8: 32996178-33044855 ; \mathrm{t}=\mathrm{ENST} 00000500843)$. To the best of our knowledge, there are no previous reports regarding its molecular mechanisms and clinical significance in lung adenocarcinoma and PTX resistance. In a previous study examining the microarray expression profile of lncRNAs in PTX-resistant A549 cells, it was identified that lncRNA ENST00000500843 expression was significantly downregulated in A549/PTX cells (20). Additionally, the results of the present study demonstrated that lncRNA ENST00000500843 expression was downregulated in lung adenocarcinoma tissues. The greater the downregulation of lncRNA ENST00000500843, the larger the diameter and the worse the pathological differentiation of the lung cancer. Lymphatic invasion was also frequently observed in such cases. This suggested that lncRNA ENST00000500843 may be involved in the incidence and development of lung cancer, and may function as a tumor suppressor. This hypothesis is supported by results from several other studies. For example, IncRNA-LINC00961 has been reported to be significantly downregulated in human NSCLC, and it could act as a tumor suppressor partially via affecting $\beta$-catenin expression (23). Zhang et al (24) demonstrated that IncRNA carbamoyl-phosphate synthase 1-HAUS augmin like complex subunit 3 expression is significantly decreased in colorectal carcinoma tissue and cell lines, and that it has a tumor-suppressive role in colorectal carcinoma.

As larger diameter and worse pathologic differentiation of tumors are generally associated with poorer prognosis of patients, one may speculate that lncRNA ENST00000500843 may affect the prognosis of patients with lung adenocarcinoma (25-28). The present study further investigated the association between ENST00000500843 expression and the OS and PFS rates of 56 patients. The data indicated that patients with low expression levels of ENST00000500843 had poorer OS and PFS rates compared with patients in the high expression group. This suggested that low expression levels of ENST00000500843 had a negative impact on the prognosis. Therefore, the clinical situation and survival of patients with lung adenocarcinoma may be predicted by studying the expression levels of ENST00000500843, making this lncRNA a potential candidate biomarker for the prognosis of lung adenocarcinoma.

Additionally, knockdown of lncRNA ENST00000500843 by siRNA-7 in A549 cells could inhibit cell apoptosis when treated with $10 \mathrm{ng} / \mathrm{ml}$ PTX, suggesting that, partly through the cell apoptosis signaling pathway, ENST00000500843 served a vital role in the regulation of PTX resistance. Overexpression of this lncRNA may result in increased sensitivity to PTX and provides a potential gene target for designing combination therapies with PTX. Although there are some lncRNAs which have been reported to be involved in PTX resistance of different types of cancer (29-32), the present study expanded the understanding of lncRNAs in the development and progression of lung adenocarcinoma and PTX resistance.

However, there were some limitations of the present study. Firstly, the present study focused on only one PTX-resistant lung adenocarcinoma cell line, and there is no data in PTX resistant tumor tissues, which made the experimental conclusions not sufficient. PTX resistant tumor tissues should be collected in future studies. Secondly, the present study only illustrated that the target IncRNA ENST00000500843 regulated PTX resistance in A549 cells via the cell apoptosis signaling pathway. However, the exact mechanisms by which lncRNA ENST00000500843 regulated the apoptosis signaling pathway are not known and require further investigation. Other experiments, including colony formation, spheroid generation and migration/invasion phenotype assays, should be performed in future studies.

In conclusion, the findings of the present study demonstrated that lncRNA ENST00000500843 was downregulated in human lung adenocarcinoma tissue and A549/PTX cells, may function as a tumor suppressor element, and that its expression was associated with tumor diameter, the degree of pathological differentiation and metastasis of lymph nodes. Additionally, patients with low expression levels of lncRNA ENST00000500843 exhibited poorer OS and PFS rates, implying that low expression levels of ENST00000500843 led to a worse prognosis. Additionally, the present study revealed that IncRNA ENST00000500843 partially regulated PTX resistance in A549 cells via the cell apoptosis signaling pathway. The present study improved the understanding of the function and clinical significance of lncRNA ENST00000500843 in the development of lung adenocarcinoma and PTX resistance, thereby establishing that IncRNA ENST00000500843 could be used as a novel marker to diagnose lung adenocarcinoma and evaluate the response to PTX-based chemotherapy. This could assist clinicians in identifying patients who would most likely benefit from chemotherapy. Future investigations into the molecular mechanisms and protein function are however required in vivo and in vitro.

\section{Acknowledgements}

Not applicable.

\section{Funding}

No funding was received.

\section{Availability of data and materials}

All data generated or analyzed during the present study are included in this published article. 


\section{Authors' contributions}

XT and ZZ conceived and designed the study. XT, SG, YL and YX performed the experiments. SG, and RW acquired and analyzed the data. XT and ZZ contributed to drafting and revising the manuscript. All authors read and approved the final manuscript.

\section{Ethics approval and consent to participate}

The present study was approved by the Ethics Committee of Shengjing Hospital of China Medical University. All patients provided written informed consent prior to the study start.

\section{Patient consent for publication}

Not applicable.

\section{Competing interests}

The authors declare that they have no competing interests.

\section{References}

1. Jochems A, El-Naqa I, Kessler M, Mayo CS, Jolly S, Matuszak M, Faivre-Finn C, Price G, Holloway L, Vinod S, et al: A prediction model for early death in non-small cell lung cancer patients following curative-intent chemoradiotherapy. Acta Oncol 57: 226-230, 2018

2. Roengvoraphoj O, Wijaya C, Eze C, Li M, Dantes M, Taugner J, Tufman A, Huber RM, Belka C and Manapov F: Analysis of primary tumor metabolic volume during chemoradiotherapy in locally advanced non-small cell lung cancer. Strahlenther Onkol 194: 107-115, 2018.

3. Guilbault C, Garant A, Faria S, Owen S, Ofiara L, Duclos M, Hirsh V and Kopek N: Long-term outcomes of induction carboplatin and gemcitabine followed by concurrent radiotherapy with low-dose paclitaxel and gemcitabine for stage III non-small-cell lung cancer. Clin Lung Cancer 18: 565-571, 2017.

4. Morgensztern D, Ng SH, Gao F and Govindan R: Trends in stage distribution for patients with non-small cell lung cancer: A National Cancer Database survey. J Thorac Oncol 5: 29-33, 2010

5. Jiang N, Dong XP, Zhang SL, You QY, Jiang XT and Zhao XG: Triptolide reverses the Taxol resistance of lung adenocarcinoma by inhibiting the NF- $\kappa \mathrm{B}$ signaling pathway and the expression of NF- $\kappa$ B-regulated drug-resistant genes. Mol Med Rep 13: 153-159, 2016

6. Liu R, Liu X, Zheng Y, Gu J, Xiong S, Jiang P, Jiang X, Huang E, Yang Y, Ge D and Chu Y: MicroRNA-7 sensitizes non-small cell lung cancer cells to paclitaxel. Oncol Lett 8: 2193-2200, 2014.

7. Holleman A, Chung I, Olsen RR, Kwak B, Mizokami A, Saijo N, Parissenti A, Duan Z, Voest EE and Zetter BR: miR-135a contributes to paclitaxel resistance in tumor cells both in vitro and in vivo. Oncogene 30: 4386-4398, 2011.

8. Datta S, Choudhury D, Das A, Das Mukherjee D, Das N, Roy SS and Chakrabarti G: Paclitaxel resistance development is associated with biphasic changes in reactive oxygen species, mitochondrial membrane potential and autophagy with elevated energy production capacity in lung cancer cells: A chronological study. Tumour Biol 39: 1010428317694314, 2017.

9. Sun QL, Sha HF, Yang XH, Bao GL, Lu J and Xie YY: Comparative proteomic analysis of paclitaxel sensitive A549 lung adenocarcinoma cell line and its resistant counterpart A549-taxol. J Cancer Res Clin Oncol 137: 521-532, 2011.

10. Azuma Y, Yokobori T, Mogi A, Altan B, Yajima T, Kosaka T, Onozato R, Yamaki E, Asao T, Nishiyama M and Kuwano H: SIRT6 expression is associated with poor prognosis and chemosensitivity in patients with non-small cell lung cancer. J Surg Oncol 112: 231-237, 2015.

11. Yang Y, Li H, Hou S, Hu B, Liu J and Wang J: The noncoding RNA expression profile and the effect of IncRNA AK126698 on cisplatin resistance in non-small-cell lung cancer cell. PLoS One 8: e65309, 2013.
12. Li Z, Zhao X, Zhou Y, Liu Y, Zhou Q, Ye H, Wang Y, Zeng J, Song Y, Gao W, et al: The long non-coding RNA HOTTIP promotes progression and gemcitabine resistance by regulating HOXA13 in pancreatic cancer. J Transl Med 13: 84, 2015.

13. Liu B, Pan CF, Ma T, Wang J, Yao GL, Wei K and Chen YJ: Long non-coding RNA AK001796 contributes to cisplatin resistance of non-small cell lung cancer. Mol Med Rep 16: 4107-4112, 2017.

14. Lee H, Kim C, Ku JL, Kim W, Yoon SK, Kuh HJ, Lee JH, Nam SW and Lee EK: A long non-coding RNA snaR contributes to 5-fluorouracil resistance in human colon cancer cells. Mol Cells 37: 540-546, 2014

15. Liu Z, Sun M, Lu K, Liu J, Zhang M, Wu W, De W, Wang Z and Wang R: The long noncoding RNA HOTAIR contributes to cisplatin resistance of human lung adenocarcinoma cells via downregualtion of p21(WAF1/CIP1) expression. PLoS One 8: e77293, 2013.

16. Dong S, Qu X, Li W, Zhong X, Li P, Yang S, Chen X, Shao M and Zhang L: The long non-coding RNA, GAS5, enhances gefitinib-induced cell death in innate EGFR tyrosine kinase inhibitor-resistant lung adenocarcinoma cells with wide-type EGFR via downregulation of the IGF-1R expression. J Hematol Oncol 8: 43, 2015.

17. Shi Y, Lv C, Shi L and Tu G: MEG3 inhibits proliferation and invasion and promotes apoptosis of human osteosarcoma cells. Oncol Lett 15: 1917-1923, 2018.

18. Xia Y, He Z, Liu B, Wang P and Chen Y: Downregulation of Meg3 enhances cisplatin resistance of lung cancer cells through activation of the WNT/ $\beta$-catenin signaling pathway. Mol Med Rep 12: 4530-4537, 2015

19. Liu J, Wan L, Lu K, Sun M, Pan X, Zhang P, Lu B, Liu G and Wang Z: The long noncoding RNA MEG3 contributes to cisplatin resistance of human lung adenocarcinoma. PLoS One 10: $\mathrm{e} 0114586,2015$.

20. Tian X, Zhang H, Zhang B, Zhao J, Li T and Zhao Y: Microarray expression profile of long non-coding RNAs in paclitaxel-resistant human lung adenocarcinoma cells. Oncol Rep 38: 293-300, 2017.

21. Livak KJ and Schmittgen TD: Analysis of relative gene expression data using real-time quantitative PCR and the 2(-Delta Delta C(T)) method. Methods 25: 402-408, 2001.

22. Amin MB, Edge SB, Greene FL, Byrd DR, Brookland RK, Washington MK, Gershenwald JE, Compton CC, Hess KR, Sullivan DC, et al (eds.): American Joint Committee on Cancer (AJCC): AJCC Cancer Staging Manual. 8th edition. Springer, New York, NY, 2017.

23. Jiang B, Liu J, Zhang YH, Shen D, Liu S, Lin F, Su J, Lin QF, Yan S, Li Y, et al: Long noncoding RNA LINC00961 inhibits cell invasion and metastasis in human non-small cell lung cancer. Biomed Pharmacother 97: 1311-1318, 2018.

24. Zhang W, Yuan W, Song J, Wang S and Gu X: lncRna CPS1-IT1 suppresses cell proliferation, invasion and metastasis in colorectal cancer. Cell Physiol Biochem 44: 567-580, 2017.

25. Li J, Zhang M, An G and Ma Q: lncRNA TUG1 acts as a tumor suppressor in human glioma by promoting cell apoptosis. Exp Biol Med (Maywood) 241: 644-649, 2016

26. Luo Y, Xuan Z, Zhu X, Zhan P and Wang Z: Long non-coding RNAs RP5-821D11.7, APCDD1L-AS1 and RP11-277P12.9 were associated with the prognosis of lung squamous cell carcinoma. Mol Med Rep 17: 7238-7248, 2018.

27. Chen Y, Wei G, Xia H, Tang Q and Bi F: Long noncoding RNA-ATB promotes cell proliferation, migration and invasion in gastric cancer. Mol Med Rep 17: 1940-1946, 2018.

28. Ding J, Li D, Gong M, Wang J, Huang X, Wu T and Wang C: Expression and clinical significance of the long non-coding RNA PVT1 in human gastric cancer. Onco Targets Ther 7: 1625-1630, 2014.

29. Ren K, Xu R, Huang J, Zhao J and Shi W: Knockdown of long non-coding RNA KCNQ1OT1 depressed chemoresistance to paclitaxel in lung adenocarcinoma. Cancer Chemother Pharmacol 80: 243-250, 2017.

30. Wang Q, Zhang W and Hao S: IncRNA CCAT1 modulates the sensitivity of paclitaxel in nasopharynx cancers cells via miR-181a/CPEB2 axis. Cell Cycle 16: 795-801, 2017.

31. Ren S, Li G, Liu C, Cai T, Su Z, Wei M, She L, Tian Y, Qiu Y, Zhang $\mathrm{X}$, et al: Next generation deep sequencing identified a novel lncRNA $n 375709$ associated with paclitaxel resistance in nasopharyngeal carcinoma. Oncol Rep 36: 1861-1867, 2016.

32. Xu J, Wu J, Fu C, Teng F, Liu S, Dai C, Shen R and Jia X: Multidrug resistant lncRNA profile inchemotherapeutic sensitive and resistant ovarian cancer cells. J Cell Physiol 233: 5034-5043, 2018. 